\title{
Radiosensitization of esophageal carcinoma cells by knockdown of HMGB1 expression
}

\author{
XUEYUAN ZHANG ${ }^{1}$, XINGXIAO YANG ${ }^{2}$, SHUCHAI ZHU ${ }^{1}$, QIAOFANG LI ${ }^{1}$ and NAIYI ZOU ${ }^{1}$ \\ Departments of ${ }^{1}$ Radiation Oncology and ${ }^{2}$ Infection Management, The Fourth Hospital of Hebei Medical University, \\ Shijiazhuang, Hebei 050011, P.R. China
}

Received June 6, 2018; Accepted November 30, 2018

DOI: 10.3892/or.2018.6923

\begin{abstract}
Radiotherapy (RT) is a traditional and important treatment for carcinoma of the esophagus along with surgery and chemotherapy. High mobility group box 1 (HMGB1) plays a crucial part in inhibiting the apoptosis of cancer cells after irradiation treatment. The present study, was designed to analyze the function of HMGB1 in esophageal cancer progression and elucidate the effects of HMGB1 on the radiosensitivity of human esophageal cancer cell lines. In the present study, an immunohistochemical evaluation of HMGB1 was performed on 77 biopsies, and the results revealed that HMGB1 overexpression was positively correlated with gross tumor volume (GTV), tumor-node-metastasis (TNM) stage, T classification, distant metastasis, and relapse and negatively correlated with patient survival rates, suggesting that HMGB1 acts as a key factor in the development of esophageal cancer. An shRNA targeting HMGB1 was designed for the knockdown of HMGB1 in ECA109 and TE13 cells, and the transfection efficiency of the shRNA was assessed using quantitative real-time reverse transcription polymerase chain reaction and western blot analysis. CCK-8 and clonogenic assays were used to analyze the effect of HMGB1 on the proliferation and radiosensitivity, respectively, of esophageal cancer cells in vitro. The influence of HMGB1 on radiation-induced changes in the migration, invasion, and cell cycle as well as apoptosis of tumor cells was examined by wound-healing and Transwell assays and flow cytometry, respectively. In addition, xenograft tumor models were constructed to observe the effect of HMGB1 on tumor growth in vivo. The results of the study in vitro revealed that the proliferation of the HMGB1-shRNA group decreased after irradiation, and the radiation treatment reduced the tumor volume of the xenograft model which was more marked in HMGB1-shRNA group. Moreover, HMGB1 was involved in
\end{abstract}

Correspondence to: Professor Shuchai Zhu, Department of Radiation Oncology, The Fourth Hospital of Hebei Medical University, 12 Jiankang Road, Shijiazhuang, Hebei 050011, P.R. China

E-mail: sczhu1965@163.com

Key words: ESCC, DNA damage response, HMGB1, radiosensitivity, apoptosis, cell cycle the phosphorylation of $\mathrm{H} 2 \mathrm{AX}$ after irradiation, and HMGB1 knockdown blocked the cell cycle in the G0/G1 phase and increased apoptosis. HMGB1 deficiency was also correlated with the upregulation of p16, Bax and caspase- 9 and the downregulation of MMP-2, MMP-9, cyclin D1, CDK4, $\gamma \mathrm{H} 2 \mathrm{AX}$ and $\mathrm{Bcl}-2$. These data indicated that the overexpression of HMGB1 prior to treatment was correlated with poor clinical outcome in esophageal carcinoma and that knockdown HMGB1 expression in human esophageal cancer cell lines increased their radiosensitivity by allowing the induction of apoptosis and G0/G1 arrest after exposure to radiation.

\section{Introduction}

It is known that esophageal carcinoma is one of the most commonly diagnosed digestive carcinomas, with $\sim 455,800$ new cases and 400,200 cancer-related deaths worldwide in 2012 (1). However, the incidence of esophageal carcinoma varies widely in different regions. According to statistics, there are more esophageal cancer patients with squamous cell carcinoma as the predominant form in Turkey, northern and central China, Kazakhstan, and northeastern Iran, a geographical region that is collectively known as the Asian Belt (2). In recent years, considerable improvement has been achieved in treatment strategies, particularly for the use of irradiation, which is an essential therapy among therapies for patients with esophageal cancer. However, the local recurrence rate after chemoradiotherapy remains high at $25-40 \%$, and the overall 5 -year survival rate is only $\sim 20 \%$ among patients with esophageal cancer (3). Since tumors recur and the prognosis is still unsatisfactory after irradiation, the study of the mechanism of radioresistance of esophageal squamous cell carcinoma (ESCC) should be encouraged to develop new therapeutic targets as assistance for radiotherapy (RT).

The protein named high mobility group box 1 (HMGB1) is a conserved and ubiquitous non-histone chromosomal protein that functions as a DNA chaperone in the processes of transcription, replication, recombination and repair $(4,5)$. The ability of HMGB1, which is located in the nucleus, to bind to small recesses in DNA promotes the binding of $\mathrm{p} 53$ with DNA at its cognate binding site in chromatin. Furthermore, HMGB1 is involved in DNA damage repair induced by various factors, particularly physical stimulations and chemical elements, and plays a decisive role in that process $(6,7)$. 
According to previous studies, HMGB1 was revealed to be strongly associated with the occurrence and progression of tumors, and its expression level has been connected with the radiosensitivity of various types of cancers (8-11), however, the underlying mechanism is unclear. In the present study, the expression level of HMGB1 was detected in both esophageal cancer tissues and cell lines. Based on the results of the HMGB1 expression level detection, we designed the following in vitro and in vivo studies to establish the impact of suppressing HMGB1 expression in human esophageal squamous carcinoma. In particular, the influence of HMGB1 on the radiosensitivity of the ECA109 and TE13 cell lines in vitro was thoroughly studied.

\section{Materials and methods}

Immunohistochemical (IHC) staining. From January 2008 to December 2013, a total of 77 endoscopic biopsy specimens from patients who were diagnosed with esophageal squamous carcinoma and received chemoradiotherapy (CRT) were obtained at The Fourth Hospital of Hebei Medical University (Hebei, China). We acquired the approval from patients and the Ethics Committee of the Fourth Hospital of Hebei Medical University for the usage of the specimens for research. We sectioned 4- $\mu \mathrm{m}$-thick slides from paraffin blocks, deparaffinized the slides in alcohol solutions with gradient concentrations, rehydrated the slides with distilled water, and then soaked the slides with citrate buffer and boiled them for $3 \mathrm{~min}$ for heat-induced antigen retrieval. After blocking the endogenous peroxidases with hydrogen peroxide solution for $15 \mathrm{~min}$, normal goat serum (5\%) was used to block non-specific antibody binding for $30 \mathrm{~min}$, and then the sections were incubated with anti-HMGB1 monoclonal antibody (dilution 1:400; cat. no. ab79823; Abcam, Cambridge, MA, USA) at $4^{\circ} \mathrm{C}$ overnight. Then, goat anti-rabbit polyclonal antibody (dilution 1:100; cat. no. SP-9000; Beijing Zhongshan Golden Bridge Biotechnology Co., Ltd., Beijing, China) and horseradish peroxidase-conjugated streptavidin working solution were each used to cover the histological sections at $37^{\circ} \mathrm{C}$ for $30 \mathrm{~min}$ successively. Subsequently, the DAB substrate-chromogen solution was applied to the sample to produce a color reaction. According to the scoring standard of previous studies $(12,13)$, 2 pathologists who were blinded to the clinical parameters of the patients interpreted the immunohistochemical results for the final analysis.

Cell line culture and X-ray irradiation. TE13, KYSE180, KYSE30, YES2 and ECA109 human esophageal cancer cell lines were cultured in RPMI-1640 medium (Gibco; Thermo Fisher Scientific, Inc., Waltham, MA, USA) with the addition of $10 \%$ fetal bovine serum (FBS; Invitrogen; Thermo Fisher Scientific, Inc.) and 1\% penicillin/streptomycin (Gibco; Thermo Fisher Scientific, Inc.). The TE13 cell line is same with TE2, TE3, TE7 and TE12 (14), and it has been authenticated by STR profiling.

All cells were maintained in Thermo Fisher Scientific, Inc., $\mathrm{CO}_{2}$-incubators with the temperature set at $37^{\circ} \mathrm{C}$ and the concentration of carbon dioxide set to $5 \%$.

Esophageal tumor cells were irradiated by a $6-\mathrm{MV}$ Siemens linear accelerator (Siemens, Buffalo Grove, IL, USA) with a source-skin distance $(\mathrm{SSD})$ of $100 \mathrm{~cm}$ and dose rate maintained at $5 \mathrm{~Gy} / \mathrm{min}$. Then, the cells were collected at certain time-points for further study.

Cell transfection. Cell transfection was performed with human HMGB1 small interfering RNA (shRNA) and negative control shRNA (PPL, Genebio Technology, Inc., Nanjing, China) using Lipofectamine 2000 (Invitrogen; Thermo Fisher Scientific, Inc.) under the guidance of the manufacturer's instructions. The concentrated virus solution and esophageal cancer cells were co-cultured, and the fluorescence of the cells was observed by optical microscopy to confirm successful transfection. The sequences were as follows: HMGB1-shRNA sense, 5'-GGGAGGAGCAUAAGAAGAATT-3' and antisense, 5'-UUCUUCUUAUGCUCCUCCCTT-3'; NC shRNA sense, 5'-UUCUCCGAACGUGUCACGUTT-3' and antisense, 5'-ACGUGACACGUUCGGAGAATT-3'.

Quantitative real-time reverse transcription polymerase chain reaction. RNA was extracted from esophageal tumor cells with TRIzol reagent (Takara Bio, Inc., Shiga, Japan), and then reversed-transcribed to cDNA with a RevertAid First Strand cDNA Synthesis Kit (Thermo Fisher Scientific, Inc.). Then, RT-PCR was applied to analyze the expression of the HMGB1 gene using Platinum SYBR-Green qPCR SuperMix-UDG (Invitrogen; Thermo Fisher Scientific, Inc.) according to the manufacturer's instructions. First, the synthetic cDNA was denatured at $94^{\circ} \mathrm{C}$ for $30 \mathrm{sec}$, then used for the following cycle: Denaturing cDNA at $94^{\circ} \mathrm{C}$ for $5 \mathrm{sec}$, annealing cDNA at $56^{\circ} \mathrm{C}$ for $15 \mathrm{sec}$ and extending cDNA at $72^{\circ} \mathrm{C}$ for $10 \mathrm{sec}, 40$ cycles in total. The GAPDH gene was used for normalization of RT-qPCR data. The $2^{-\Delta \Delta C T}$ method was applied to analyze HMGB1 gene expression (15).

Western blot analysis. We conducted western blot analysis following a method previously described (16). The relevant antibodies were anti-HMGB1 (dilution 1:10,000; cat. no. ab79823), anti- $\gamma \mathrm{H} 2 \mathrm{AX}$ (dilution 1:1,000; cat. no. ab26350; Abcam), anti-MMP-2 (dilution 1:1,000; cat. no. 10373-2-AP), anti-MMP-9 (dilution 1:1,000; cat. no. 10375-2-AP), anti-p16 (cat. no. 10883-1-AP), anti-caspase-9 (dilution 1:1,000; cat. no. 10380-1-AP), anti-Bcl-2 (dilution 1:2,000; cat. no. 12789-1-AP), anti-CDK4 (dilution 1:2,000; cat. no. 11026-1-AP), anti-cyclin D1 (dilution 1:5,000; cat. no. 60186-1-lg), anti-Bax (dilution 1:5,000; cat. no. 50599-2-lg; ProteinTech Group, Inc., Chicago, IL, USA) and anti- $\beta$-actin (dilution 1:10,000; cat. no. AP0060; Bioworld Technology, Inc., St. Louis Park, MN, USA). The blotted protein bands were revealed by an Odyssey system (LI-COR Biosciences, Lincoln, NE, USA). Finally, the intensity of the protein bands was assessed with ImageJ (National Institutes of Health, Bethesda, MD, USA) and the ratio of the protein to corresponding $\beta$-actin was calculated to reflect the changes in expression levels. All western blot analyses were performed independently at least 3 times.

Cell proliferation assay. After preparing a cell suspension with a concentration of up to $5 \times 10^{4}$ cells $/ \mathrm{ml}, 100 \mu \mathrm{l} /$ well was seeded into 96 -well plates with 5 duplicates for each sample. At certain time-points after irradiation, the viability of the cells 
under the different treatments was determined by incubation with $10 \mu \mathrm{l}$ Cell Counting Kit-8 (CCK-8) [MedChem Express (MCE) Princeton, NJ, USA] for $2 \mathrm{~h}$. Then, the cell content was calculated by detecting the absorbance of each well at $450 \mathrm{~nm}$ via a Multiskan microplate. The experiment was repeated at least 3 times.

Clonogenic assay. Esophageal cancer cells irradiated with a set of graded doses were cultured in 6-well culture plates for 15 days in triplicate. After the formation of cell clones, crystal violet $(0.6 \%)$ was applied to stain the cells for $15 \mathrm{~min}$. Colonies containing 50 cells or more were taken into account. Basic data was input into GraphPad Prism version 5.0 (GraphPad Software, Inc., La Jolla, CA, USA), and the biological parameters of radiation and cell survival curves were obtained.

Wound healing assay. Esophageal tumor cells were plated in 6-well plates. When the cells grew to confluence $>80 \%$, a straight cell-free zone was created by a $200-\mu 1$ pipette tip/well. Then the scratched areas were marked as $0 \mathrm{~h}$ and photographed using computer-assisted fluorescent microscopy. Cells were cultured in $2 \mathrm{ml}$ of media without FBS, then images were captured to observe the scratched areas at 16 and $32 \mathrm{~h}$ separately. The migration of cells with various treatments was presented as the percentage of the cell-free zone at the aforementioned time-points compared to $0 \mathrm{~h}$ and related to the control group.

Transwell assay. The invasion ability of tumor cells was detected using Transwells coated with Matrigel (both from Corning Inc., Corning, NY, USA) before use. Cells were diluted to $5 \times 10^{5} / \mathrm{ml}$ with serum-free medium and $200 \mu \mathrm{l}$ was transferred to the top chambers. Medium containing 10\% FBS was placed in the lower chamber. The cells on the upper side of the chamber were slightly wiped with a cotton swab after penetrating for $24 \mathrm{~h}$. Concurrently, the cells passing through the filter were fixed with formaldehyde and stained with crystal violet for $10 \mathrm{~min}$. Then, the number of stained cells was photographed and counted with a fluorescent microscope from 5 randomly selected fields (magnification, x200).

Cell cycle and apoptosis. Cell cycle analysis used esophageal tumor cells that were harvested and fixed with $70 \%$ precooled ethanol and maintained at $4^{\circ} \mathrm{C}$. The following day, the cells were stained with propidium iodide probe solution (BD Biosciences, San Jose, CA, USA) in the dark for $30 \mathrm{~min}$. Cell apoptosis was detected with an Annexin V-FITC apoptosis detection kit (BD Biosciences). In accordance with the kit's instructions, cells were collected and stained with propidium iodide (PI) and Annexin V-FITC. Flow cytometry was applied to detect the cell cycle distribution and apoptosis rates, encompassing both the early apoptosis (Annexin $\mathrm{V}^{+} / \mathrm{PI}^{-}$) and late apoptosis/necrosis (Annexin $\mathrm{V}^{+} / \mathrm{PI}^{+}$) phases.

Xenograft tumor models. Twelve 6-week-old male BALB/c nude mice (weight, 19 $\pm 1 \mathrm{~g}$ ) were obtained from Beijing Vital River Laboratory Animal Technology Co., Ltd. (Beijing, China), and maintained in specific pathogen-free conditions with controlled temperature $\left(23 \pm 2^{\circ} \mathrm{C}\right)$, humidity $(55 \pm 5 \%)$ and light (12 h light/dark cycle). The mice were provided with sterile food and water ad libitum. All experiments with animals were carried out with the approval of the Animal Care and Use Committee of the Fourth Hospital of Hebei Medical University. A total of $4 \times 10^{6} \mathrm{HMGB} 1-\mathrm{shRNA}$ or NC tumor cells were injected into the left hind paw of the mice. Three weeks after injection, irradiation (5 Gy) was performed each day for 3 days with a collimator container to protect the normal tissue. Calipers was used to assess the tumor diameter $(\mathrm{mm})$ twice a week, and the tumor volume (TV) was calculated by the following formula: $\mathrm{TV}=\mathrm{AB}^{2} / 2$, where $\mathrm{A}$ represents the long diameter and $\mathrm{B}$ represents the short diameter.

Statistical analysis. The data collected in the present study were analyzed using SPSS software package version 21 (SPSS, Inc., Chicago, IL, USA) and recorded as the mean \pm standard deviation (SD). The endpoint of progression-free survival (PFS) was assessed from the beginning of CRT to progression, death or the date of the last follow-up. The survival analysis was carried out by Kaplan-Meier method with log-rank test and the $\chi^{2}$ or Fisher's exact tests was used to analyze the association between clinical parameters and HMGB1 expression. The comparisons of data between different groups was performed using ANOVA with least significant difference (LSD) test. If the P-value of a two-sided statistic test was $<0.05$ or $<0.01$, the result was considered to be statistically significant.

\section{Results}

Overexpression of HMGB1 indicates an adverse prognosis in esophageal cancer. The relationship between the expression level of HMGB1 and the clinical parameters of esophageal cancer patients was analyzed. Table I revealed that the associations between the expression level of HMGB1 and sex, age, lesion location, or $\mathrm{N}$ classification $(\mathrm{P}>0.05)$ had no statistical significance. Conversely, the accumulation of HMGB1 in esophageal cancer was significantly associated with gross tumor volume (GTV) $(\mathrm{P}=0.014)$, TNM stage (7th AJCC) $(\mathrm{P}<0.001)$, T classification $(\mathrm{P}=0.003)$, relapse $(\mathrm{P}=0.003)$ and distant metastasis $(\mathrm{P}<0.001)$. Immunohistochemical staining revealed that the expression of HMGB1 in ESCC samples (Fig. 1Ab, $\mathrm{c}$ and d) was higher in comparison with adjacent tissues with no tumor complication (Fig. 1Aa). After the generation of survival curves, the HMGB1 expression level in ESCC was significantly associated with overall survival $(\mathrm{P}=0.007$; Fig. 1B) and progression-free survival $(\mathrm{P}=0.008$; Fig. $1 \mathrm{~B})$, which were both significantly shorter in patients with positive expression of HMGB1 compared with patients with negative expression of HMGB1 according to the results of the log-rank test. In summary, statistical analysis revealed the critical role that HMGB1 played in the progression of esophageal cancer, and high levels of HMGB1 indicated poor clinical prognosis.

HMGB1 is downregulated in HMGB1-shRNA cell lines. The expression of HMGB1 in the TE13, KYSE180, KYSE30, YES2 and ECA109 esophageal squamous carcinoma cell lines was determined in vitro by western blot analysis, and the results revealed higher expression levels of HMGB1 in the ECA109 and TE13 cell lines compared with the other cell lines (Fig. 1C). Thus, ECA109 and TE13 cells were chosen 
Table I. Association between the clinical characteristics and expression of HMGB1 protein.

\begin{tabular}{|c|c|c|c|c|}
\hline \multirow[b]{2}{*}{ Characteristics } & \multirow[b]{2}{*}{$\mathrm{n}$} & \multicolumn{2}{|c|}{ HMGB1 } & \multirow[b]{2}{*}{ P-value } \\
\hline & & Negative & Positive & \\
\hline \multicolumn{5}{|l|}{ Age (years) } \\
\hline$<65$ & 34 & 5 & 29 & \multirow[t]{2}{*}{0.742} \\
\hline$\geq 65$ & 43 & 5 & 38 & \\
\hline \multicolumn{5}{|l|}{ Sex } \\
\hline Male & 49 & 7 & 42 & \multirow[t]{2}{*}{0.739} \\
\hline Female & 28 & 3 & 25 & \\
\hline \multicolumn{5}{|c|}{ Gross tumor volume (GTV) } \\
\hline$<30$ & 27 & 8 & 24 & \multirow[t]{2}{*}{0.014} \\
\hline$\geq 30$ & 50 & 2 & 43 & \\
\hline \multicolumn{5}{|l|}{ Lesion location } \\
\hline Neck/upper & 28 & 4 & 24 & \multirow[t]{2}{*}{0.798} \\
\hline Middle/lower & 49 & 6 & 43 & \\
\hline \multicolumn{5}{|l|}{ TNM stage } \\
\hline I-II & 34 & 10 & 24 & \multirow[t]{2}{*}{$<0.001$} \\
\hline III-IV & 43 & 0 & 43 & \\
\hline \multicolumn{5}{|l|}{$\mathrm{T}$ classification } \\
\hline $\mathrm{T} 1-\mathrm{T} 2$ & 27 & 8 & 19 & \multirow[t]{2}{*}{0.003} \\
\hline $\mathrm{T} 3-\mathrm{T} 4$ & 50 & 2 & 48 & \\
\hline \multicolumn{5}{|l|}{$\mathrm{N}$ classification } \\
\hline N0 & 31 & 5 & 26 & \multirow[t]{2}{*}{0.766} \\
\hline N1-N3 & 46 & 5 & 41 & \\
\hline \multicolumn{5}{|c|}{ Distant metastasis } \\
\hline M0 & 16 & 7 & 9 & \multirow[t]{2}{*}{$<0.001$} \\
\hline M1 & 61 & 3 & 58 & \\
\hline \multicolumn{5}{|l|}{ Relapse } \\
\hline Negative & 15 & 6 & 9 & \multirow[t]{2}{*}{0.003} \\
\hline Positive & 62 & 4 & 58 & \\
\hline
\end{tabular}

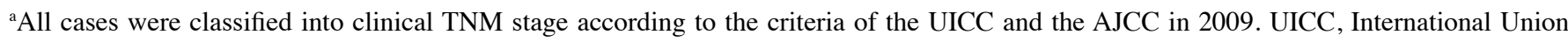
against Cancer; AJCC, American Joint Committee on Cancer; HMGB1, high mobility group box 1; TNM, tumor-node-metastasis.

for further study, and the expression of HMGB1 after transfection with an shRNA targeting HMGB1 (HMGB1-shRNA) was determined through western blot and RT-qPCR analyses. Finally, no difference was revealed in HMGB1 expression between ECA109-NC or TE13-NC cells and their corresponding parental cells. However, HMGB1 expression in HMGB1-shRNA cells relative to their corresponding parental cells was significantly reduced (Fig. 1D and E). These data indicated that HMGB1-shRNA significantly downregulated HMGB1 in esophageal cancer ECA109 and TE13 cells.

Transfection with HMGB1-shRNA inhibits proliferation and increases the radiosensitivity of esophageal tumor cells in vitro and in vivo. To investigate the biological function of HMGB1 on the cell viability of esophageal cancer cells, cells under different conditions were collected at 24, 48, 72 and $96 \mathrm{~h}$ after transfection and irradiation. The results of the CCK- 8 assay indicated that the proliferation rates of the HMGB1-shRNA groups were significantly lower at each time-point than those of the corresponding control and NC groups with or without irradiation (Fig. 2A). In addition, a colony formation assay was applied to detect the effect of the alteration of HMGB1 expression on the radiosensitivity of ECA109 and TE13 cells. After the cell survival curves were plotted based on the formed clones, and the radiobiological parameters of each group were input into statistical analysis, it was revealed that the radiosensitivity of the HMGB1-shRNA group was higher compared with those of the control and NC groups (Fig. 2B). To explore the function of HMGB1 in tumor formation in vivo, the HMGB1-shRNA and NC cells of the ECA109 cell line were implanted into nude mice. The results revealed that the tumor volume (Fig. 2C and D) and weight (Fig. 2E) in the HMGB1-shRNA group were notably smaller than those of the NC group before and after irradiation $(\mathrm{P}<0.05)$. These findings indicated that transfection with HMGB1-shRNA induced proliferation inhibition with or without irradiation 

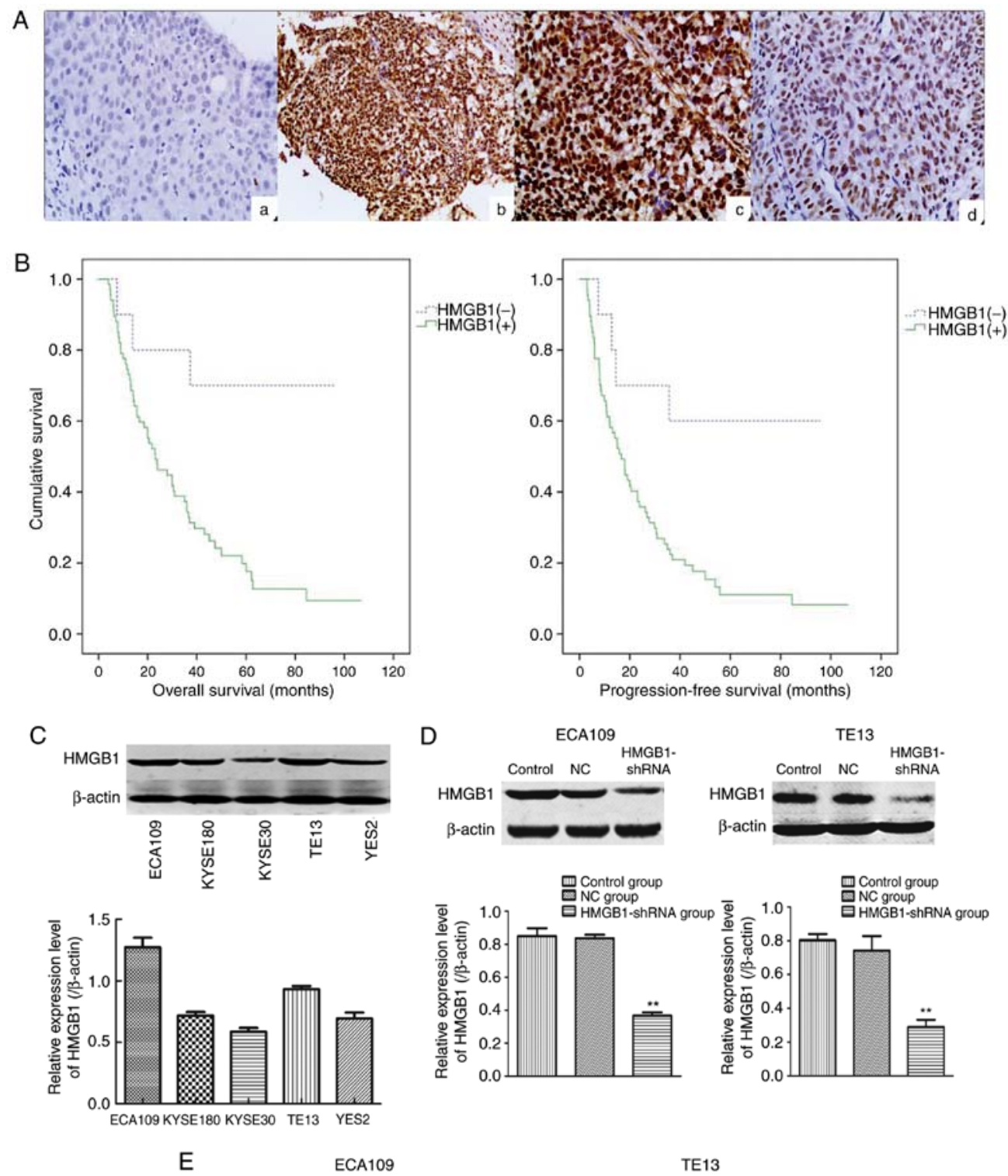

ECA109

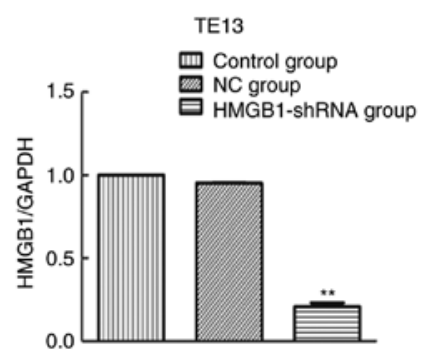

Figure 1. High expression of HMGB1 in human ESCC biopsy specimens and downregulation of HMGB1 by transfection of shRNA. (A) HMGB1 staining was predominantly localized in the nuclei. In comparison with adjacent tissues with no tumor complication (a, negative, original magnification, $\mathrm{x} 200$ ), the expression of HMGB1 in ESCC samples was higher (b and c, positive, magnification, x100 and x200, respectively; d, weakly positive, magnification, x200). (B) Overall survival and progression-free survival among HMGB1-negative and HMGB1-positive groups revealed statistical significance differences according to Kaplan-Meier survival analysis ( $\mathrm{P}<0.05$, log-rank test). (C) The comparison of the HMGB1 protein expression levels in 5 esophageal cancer cell lines was performed using western blot analysis. (D) Similarly, the suppression of HMGB1 protein expression was observed in the HMGB1-shRNA group by western blot analysis. (E) The mRNA expression of HMGB1 in the HMGB1-shRNA group were significantly downregulated after transfection in both ECA109 and TE13 cells according to the results of the RT-qPCR analysis. ${ }^{* *} \mathrm{P}<0.01$. HMGB1, high mobility group box 1 ; ESCC, esophageal squamous cell carcinoma.

and increased the radiosensitivity of esophageal cancer cells both in vitro and in vivo.

HMGB1 plays an essential role in the phosphorylation of $H 2 A X$ after irradiation. In the present study, whether HMGB1 was involved in radiation-induced DNA damage repair was assessed by analyzing the variations in HMGB1 and $\gamma \mathrm{H} 2 \mathrm{AX}$ expression after irradiation. The results of the western blot analysis revealed that ionizing radiation induced the protein expression of $\gamma \mathrm{H} 2 \mathrm{AX}$ and HMGB1 in a dose-dependent manner (Fig. 2F). In addition, the changes in expression of these 2 proteins were consistent over the course of time after irradiation (Fig. 2G), and both of them were highest at 1 and $2 \mathrm{~h}$ after exposure to $6 \mathrm{~Gy}$ irradiation, and then their expression gradually 
A

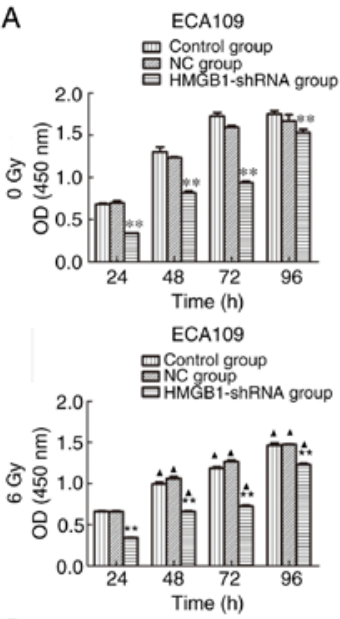

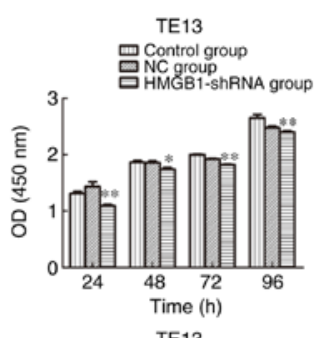

TE13

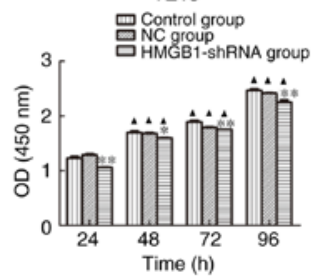

B ECA109
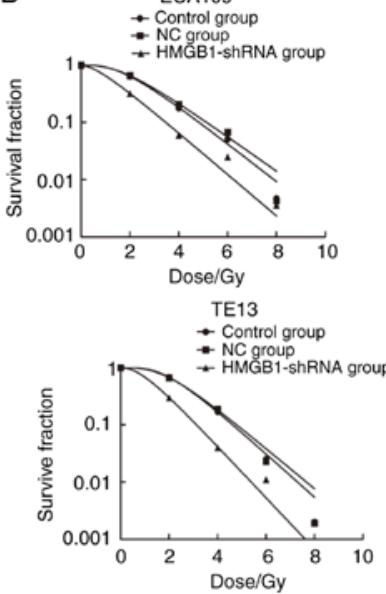

E

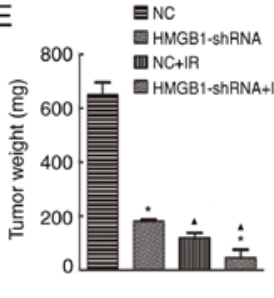

$\mathrm{F}$

ECA109

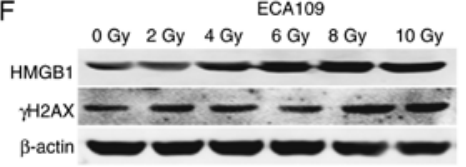

ECA109
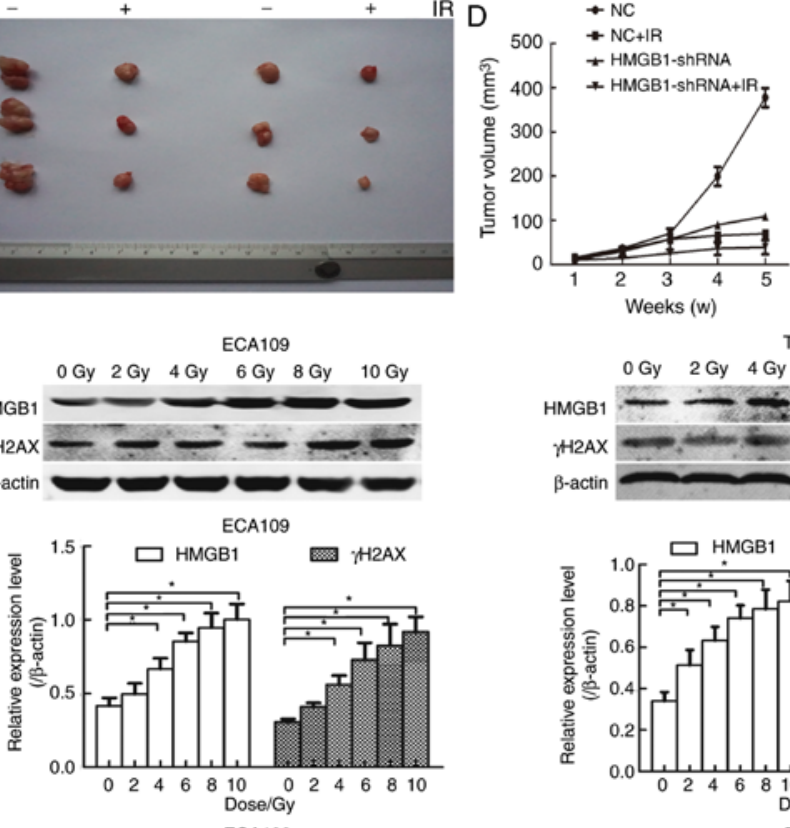

TE13

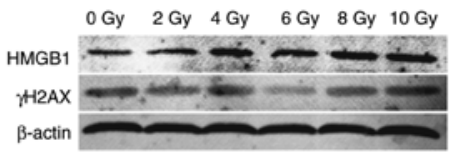

TE13

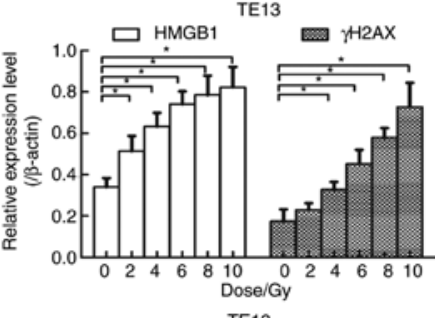

EA109

G
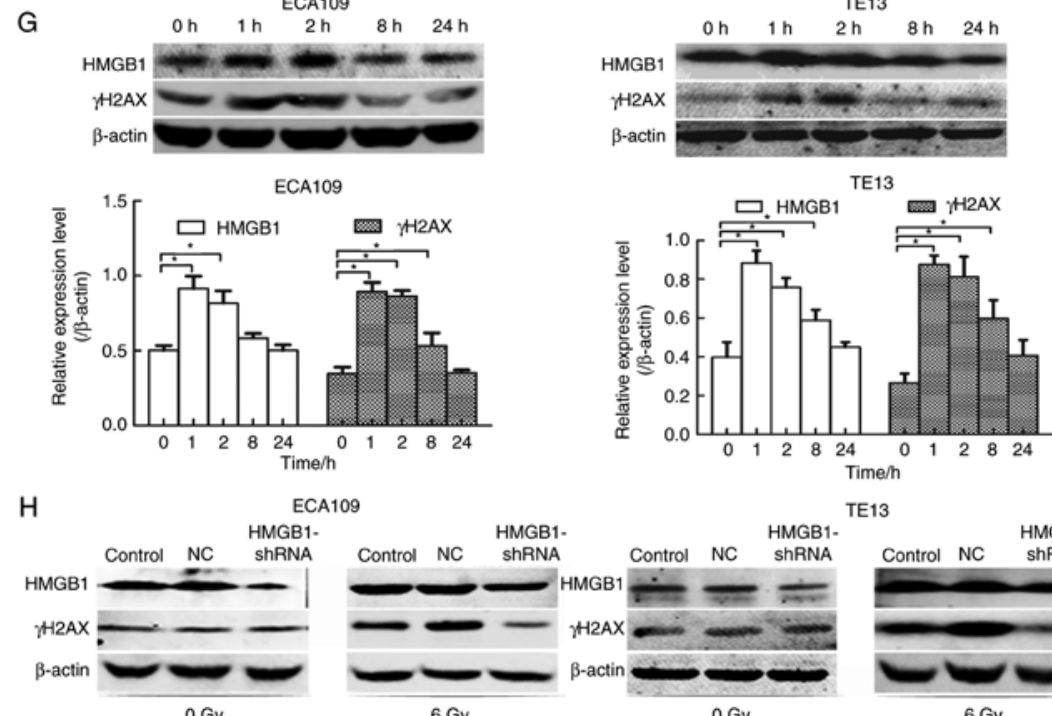

ECA109
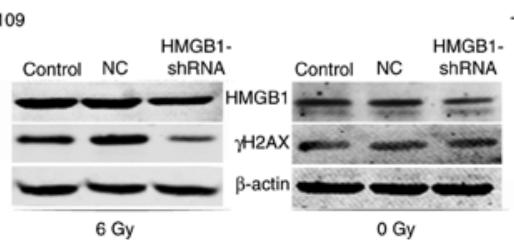

TE13

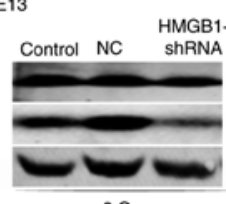

Figure 2. HMGB1 deficiency inhibited the proliferation ability of ECA109 and TE13 esophageal tumor cells and sensitized them to radiation. (A) A CCK-8 assay revealed that the growth of cells in the HMGB1-shRNA group was significantly inhibited before and after irradiation in ECA109 and TE13 cells; the number of cells was determined by the absorbance at $450 \mathrm{~nm}$. (B) A colony formation assay was performed to detect the radiosensitivity of ECA109 and TE13 cells, and the final cell survival curves of the different groups are presented. (C) The nude mice were sacrificed, and the tumors were dissected. The (D) tumor volume and (E) weights were assessed; the data are presented as the means $\pm \mathrm{SD}$. (F-H) The expression of HMGB1 and $\gamma \mathrm{H} 2 \mathrm{AX}$ was altered in parallel in ECA109 and TE13 cells after irradiation, and the $\gamma$ H2AX expression in the HMGB1-shRNA group was not increased after irradiation in ECA109 and TE13 cells. A comparison with the control or $\mathrm{NC}$ group is symbolized by the asterisks ${ }^{*} \mathrm{P}<0.05$ and ${ }^{* * *} \mathrm{P}<0.01$; a comparison with the corresponding non-irradiated group is symbolized by the triangles ${ }^{\wedge} \mathrm{P}<0.05$. CCK-8, Cell Counting Kit-8; HMGB1, high mobility group box 1 . 

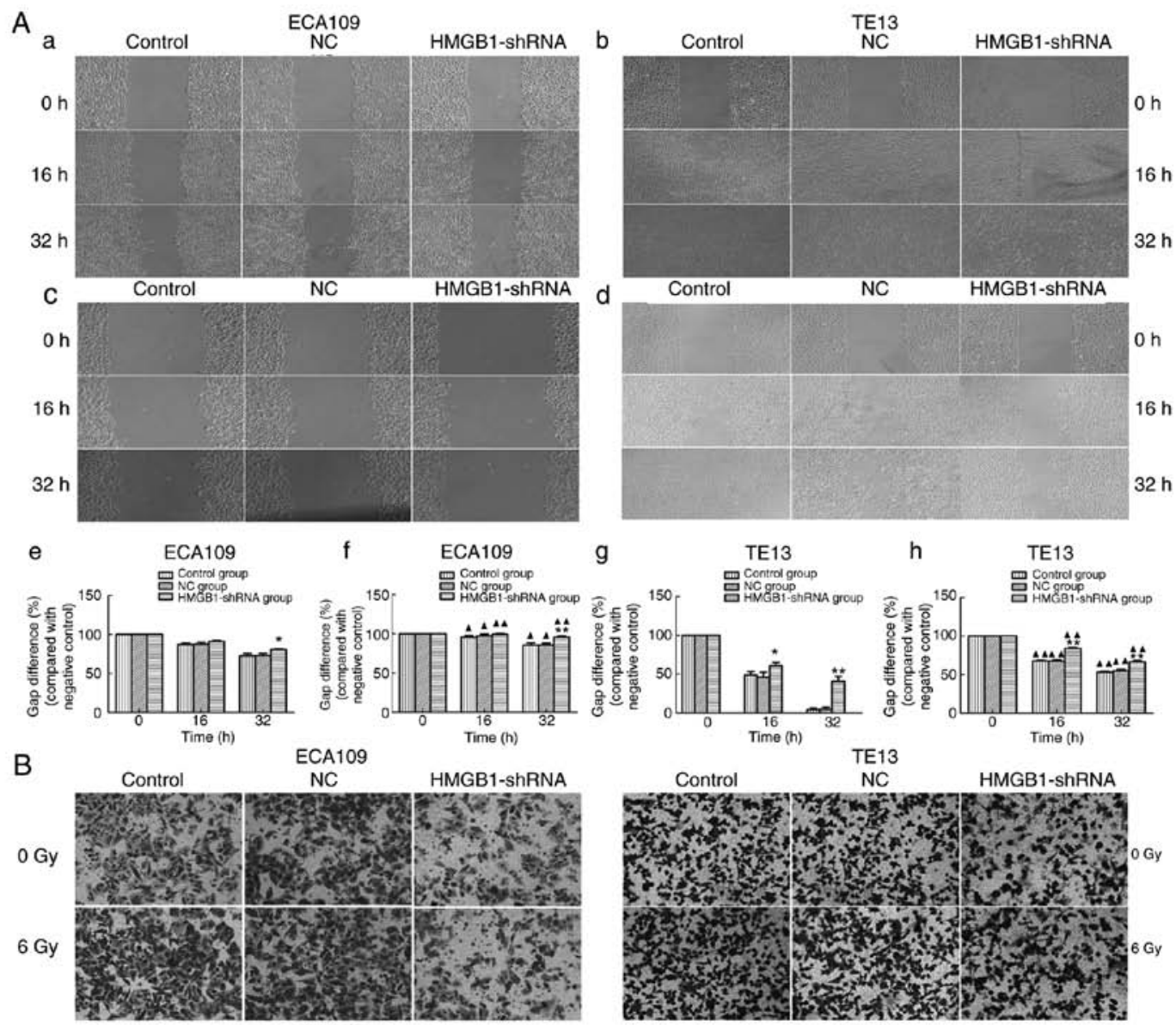

ECA109
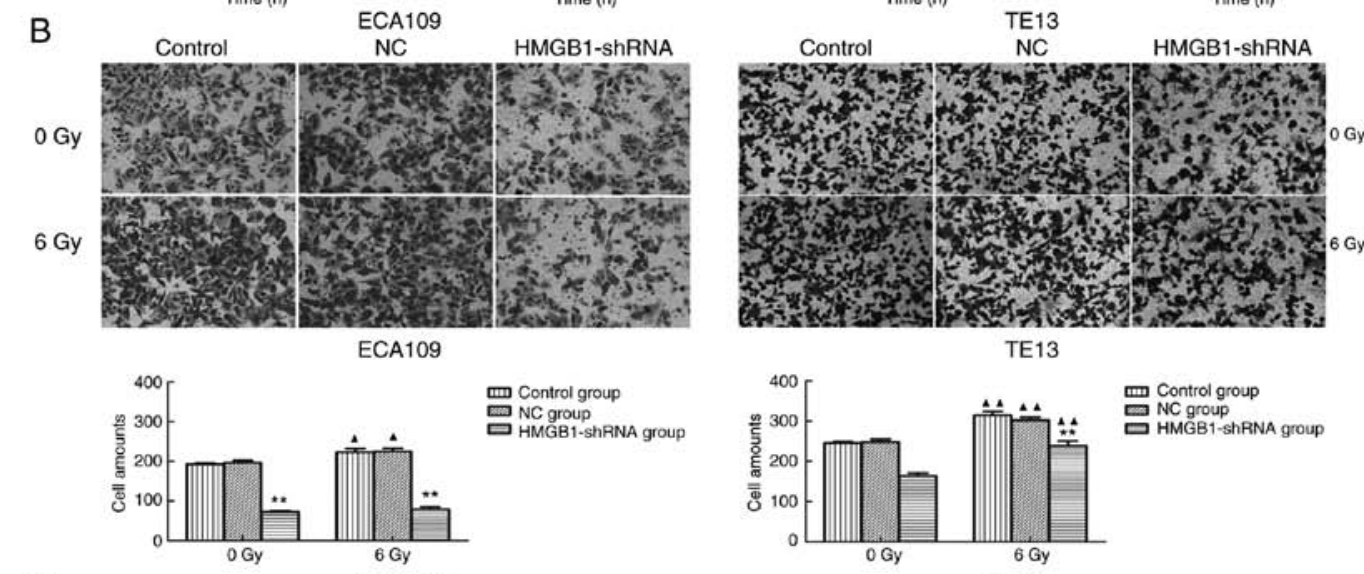

TE13

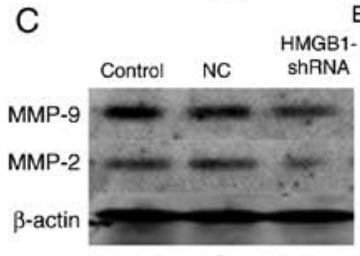

ECA109
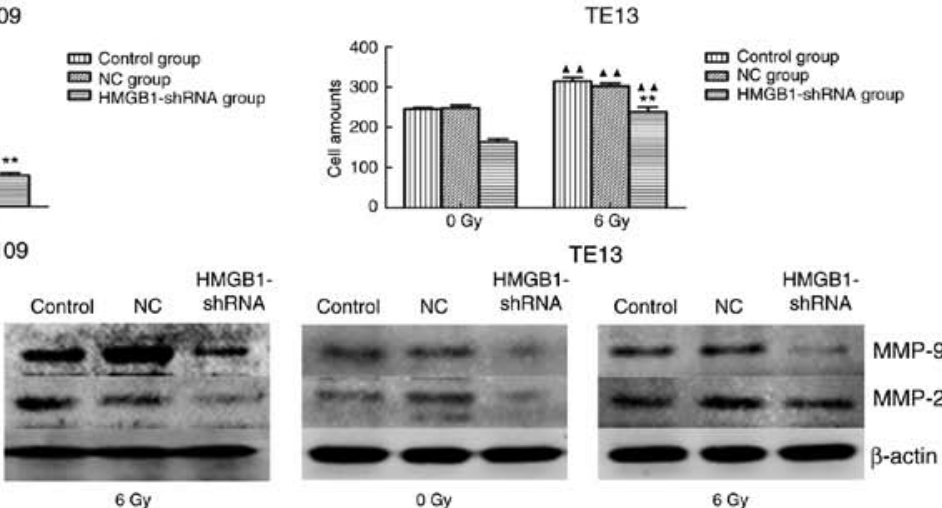

Figure 3. HMGB1 silencing inhibits cell migration and invasion. (A) The scratch area was assessed with Image-Pro Plus at different time-points and defined the area at $0 \mathrm{~h}$ as $100 \%$. The area of the other 2 time-points was defined as the percentage of the measurement compared to $0 \mathrm{~h}$. The gap area changes in the HMGB1-shRNA group were smaller than those in the negative control group at $32 \mathrm{~h}$ for (a and e) ECA109 and (b and g) TE13 cells without IR (c and $\mathrm{f}, \mathrm{d}$ and $\mathrm{h}$ ). In addition, the migration abilities of all irradiated groups were reduced both at $16 \mathrm{~h}$ and at $32 \mathrm{~h}$ compared with those of the corresponding non-irradiated group. (B) The results of the Transwell assay indicated that downregulation of HMGB1 significantly inhibited the invasion of ECA109 (left) and TE13 (right) cells. (C) The MMP proteins were downregulated in the HMGB1-shRNA group compared to the control and NC groups with or without IR. A comparison with the NC group is symbolized by the asterisks ${ }^{*} \mathrm{P}<0.05$ and ${ }^{* *} \mathrm{P}<0.01$; a comparison with the corresponding non-irradiated group is symbolized by the triangles ${ }^{\boldsymbol{}} \mathrm{P}<0.05$ and $\boldsymbol{\Delta}{ }^{\mathbf{P}} \mathrm{P}<0.01$. HMGB1, high mobility group box 1; IR, irradiation.

reduced. These findings prompted us to suppose that HMGB1 is associated with the generation of $\gamma \mathrm{H} 2 \mathrm{AX}$. Then, the level of phosphorylated $\mathrm{H} 2 \mathrm{AX}$ was detected to evaluate the influence of HMGB1 deficiency with and without irradiation. The results revealed that knockdown of HMGB1 protein in ECA109 and TE13 cells inhibited accumulation of $\gamma \mathrm{H} 2 \mathrm{AX}$ following irradiation treatment, while there were no notable changes in $\gamma \mathrm{H} 2 \mathrm{AX}$ concentrations in the non-irradiated groups (Fig. 2H). The western blot analysis demonstrated that HMGB1 deficiency inhibited the phosphorylation of $\mathrm{H} 2 \mathrm{AX}$ induced by irradiation.
HMGB1 silencing inhibits cell migration and invasion. To observe the migration and invasion abilities of esophageal carcinoma cells, a wound-healing experiment and Transwell assay, respectively, were applied to ECA109 and TE13 cells. The results revealed that blocking the expression of HMGB1 significantly decreased the migration activity of ECA109 and TE13 cell lines both with (Fig. 3Ac, d, f and h) and without irradiation (Fig. 3Aa, b, e and g). In addition, the invasive ability of esophageal carcinoma cells transfected with HMGB1-shRNA was significantly inhibited compared with those of the 
A
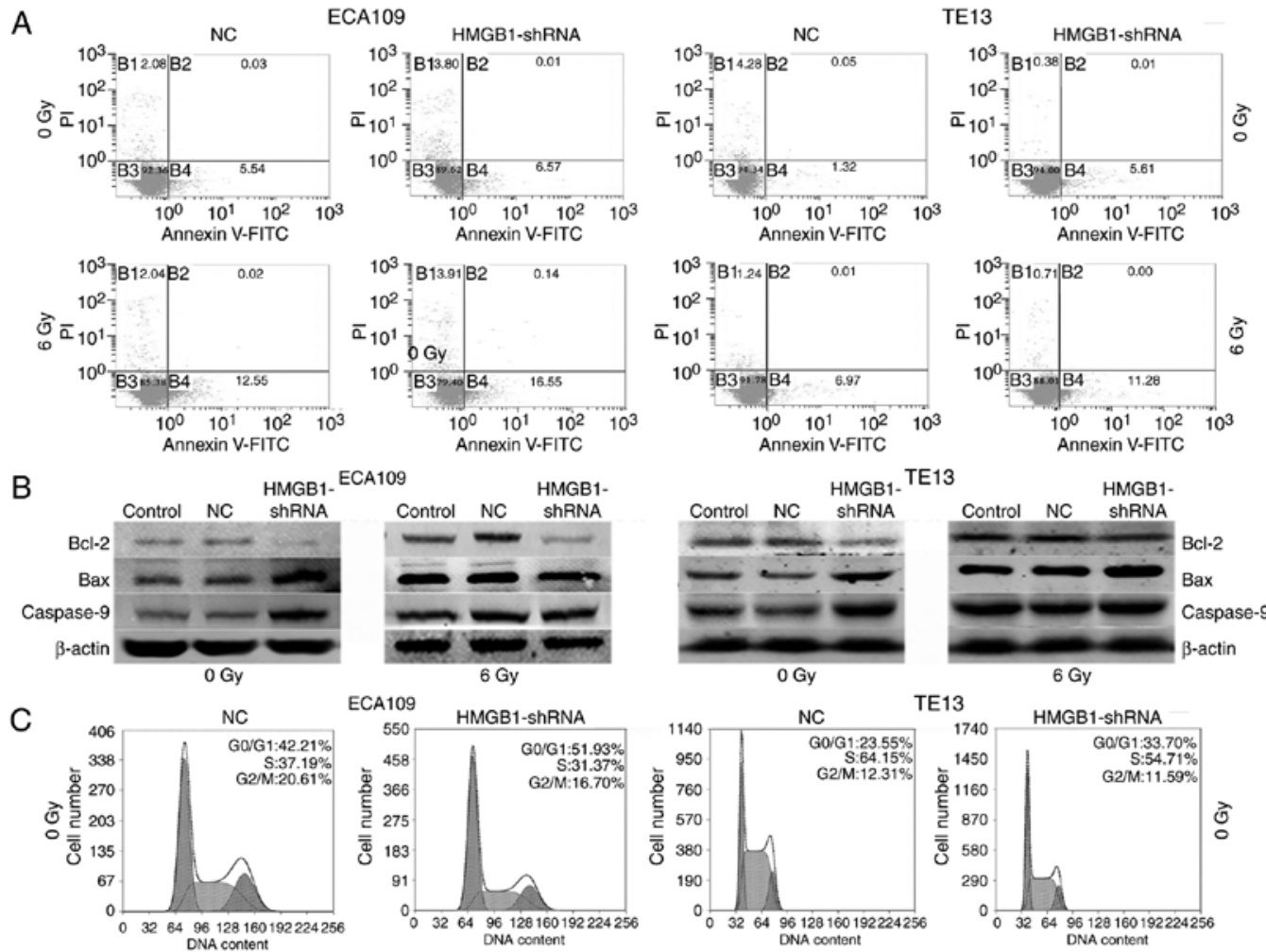

TE13 HMGB1-shRNA
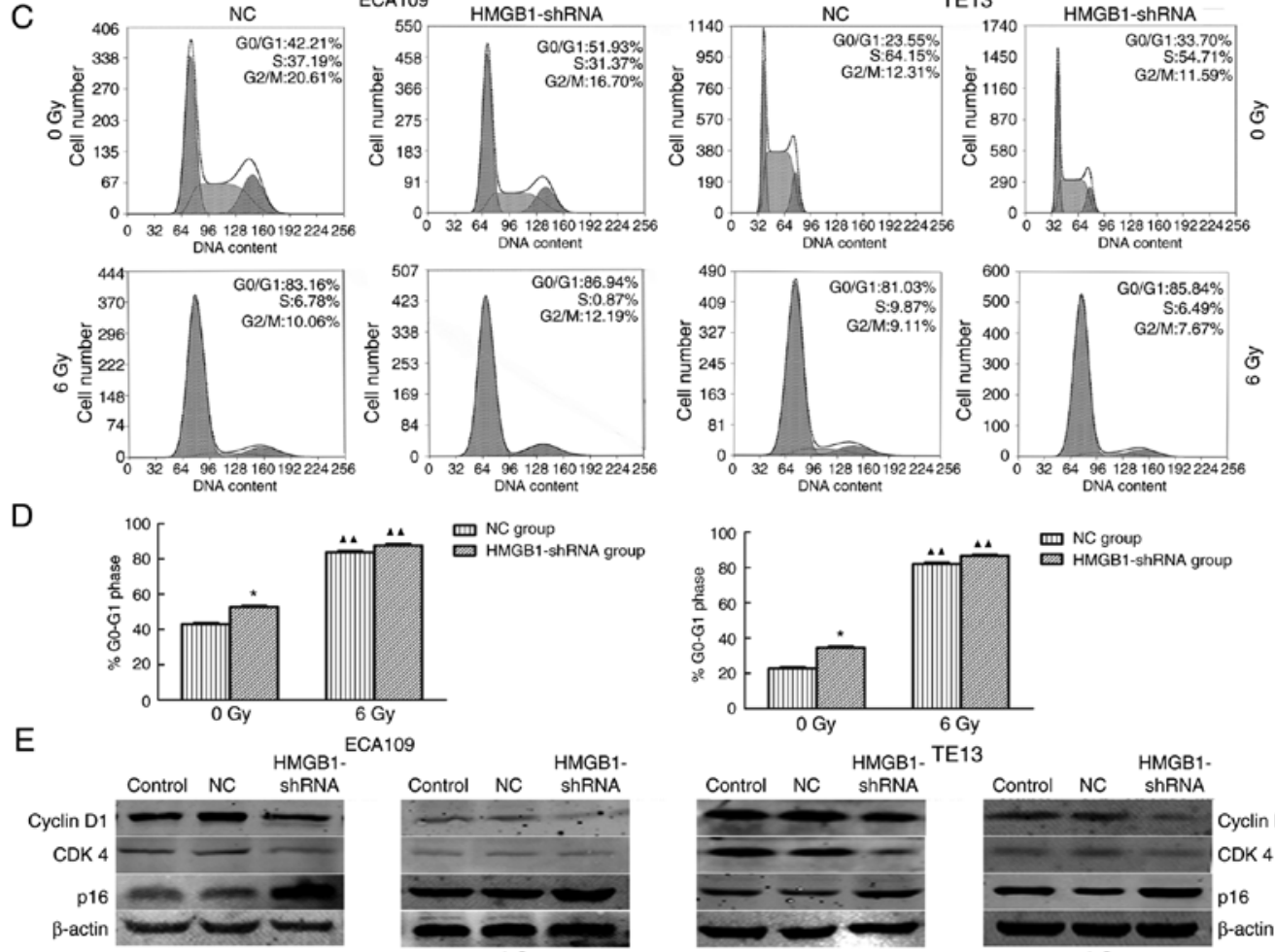

ECA109

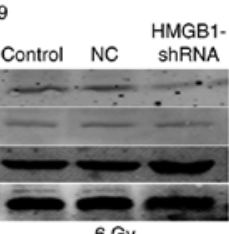

0 Gy

6 Gy

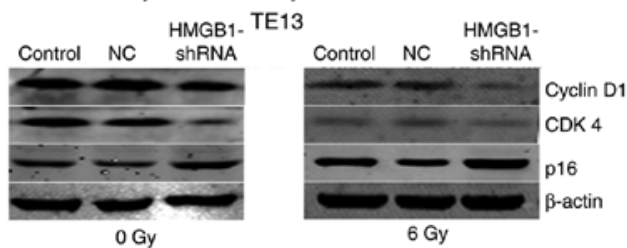

Figure 4. Suppression of HMGB1 increases the apoptosis rates of esophageal carcinoma cells after IR in vitro and affects the generation of apoptosis-related proteins. (A) The apoptotic rate was calculated as the sum of B2 and B4. As the results revealed, compared with the NC group, silencing of HMGB1 sensitized ECA109 and TE13 cells to apoptosis both with 6 Gy radiation (A, lower images) and without (A, upper images). (B) After transfection with HMGB1-shRNA, the expression of Bcl-2 was attenuated, while the expression of Bax and caspase-9 was increased in ECA109 and TE13 cells. (C) HMGB1-shRNA and irradiation induced $\mathrm{G}_{0} / \mathrm{G}_{1}$ arrest in ESCC cells. (D) The results of flow cytometry revealed that the percentages of $\mathrm{G}_{0} / \mathrm{G}_{1}$-phase cells in the HMGB1-shRNA groups were significantly higher compared to those of the NC groups before IR, and the HMGB1-shRNA group percentages significantly increased after irradiation. (E) In the HMGB1-shRNA group, the expression of cyclin D1 and CDK4 was attenuated, while the expression of p16 was increased. Additionally, irradiation inhibited cyclin D1 and CDK4 expression in esophageal tumor cells. A comparison with the $\mathrm{NC}$ group is symbolized by an asterisk ${ }^{*} \mathrm{P}<0.05$; and a comparison with the corresponding non-irradiated group is symbolized by triangle ${ }^{\mathbf{\Lambda}} \mathrm{P}<0.01$. HMGB1, high mobility group box 1; IR, irradiation.

control and $\mathrm{NC}$ groups $(\mathrm{P}<0.05)$ both with and without irradiation (Fig. 3B). These results indicated that HMGB1 deficiency decreased the migration and invasion abilities of esophageal tumor cells. Furthermore, to analyze the potential mechanism underlying the HMGB1-shRNA-mediated blockade of invasion and migration, MMP-2 and MMP-9 protein expression was examined, and the expression levels of both were reduced in the HMGB1-shRNA group before and after irradiation in comparison to those of the control and NC groups (Fig. 3C).

Suppression of HMGB1 increases the apoptosis rates of esophageal carcinoma cells after irradiation in vitro. The apoptosis rate of the HMGB1-shRNA group was higher than that of the $\mathrm{NC}$ group before irradiation as evidenced by Annexin $\mathrm{V}$ and PI staining (Fig. 4A). In addition, the HMGB1-shRNA group 
exhibited more apoptosis after irradiation than the NC group in ECA109 and TE13 cells (Fig. 4A). To thoroughly assess the mechanism, the expression of apoptosis-related proteins was detected, including Bcl-2, Bax and caspase-9, before and after irradiation by western blot analysis. The results revealed decreased expression of Bcl-2 and increased Bax and caspase-9 levels in the HMGB1-shRNA group with and without irradiation compared with the NC group (Fig. 4B). These results revealed that downregulation of HMGB1 increased the apoptosis of esophageal carcinoma cells by affecting the expression levels of Bcl-2, Bax and caspase-9.

Knockdown of HMGB1 combined with irradiation induces G0/G1 arrest in ESCC cells. According to flow cytometric results, silencing of HMGB1 caused G0/G1 arrest of esophageal carcinoma cells with and without irradiation (Fig. 4C and D). A western blot assay that explored the expression levels of proteins related to the cell cycle revealed downregulation of cyclin D1 and CDK4 and upregulation of p16 in the HMGB1-shRNA groups with and without irradiation compared with the levels in the NC group (Fig. 4E). The cyclin D1 expression was lower in the irradiated group than the non-irradiated group. Furthermore, cyclin D1 expression was significantly decreased in the HMGB1-shRNA group with irradiation treatment. These data demonstrated that suppressing the expression of HMGB1 arrested esophageal tumor cells in the G0/G1 phase by upregulating the expression of p16 and decreasing the expression cyclin D1 and CDK4.

\section{Discussion}

Although combined chemoradiotherapy has improved the prognosis for esophageal cancer, the prognosis remains poor. Less than half of esophageal cancer patients survive 2 years without recurrence after chemoradiation therapy with or without surgery (17). One critical reason is that tumors of the esophagus are found too late to perform radical and curative surgery. In addition, esophageal cancer frequently occurs with distal metastases, including in the lungs, bones, brain and liver, when it is diagnosed. For advanced cases, radiotherapy combined with chemotherapy is the mainstay treatment. Therefore, the discovery of effective therapeutic targets to enhance radiosensitivity may improve the survival of ESCC patients.

The overexpression of HMGB1 has been implicated in multiple cancers, including breast (18), rectal (11), bladder (19) and gallbladder cancer (20), pleural mesothelioma (21), nasopharyngeal carcinoma (22), and esophageal cancer (23). During tumor development and cancer treatment, diverse roles for HMGB1 have been revealed in previous studies, including roles in inflammation (24), immune responses (25), angiogenesis (26), DNA damage repair (27), autophagy (28), proliferation, apoptosis, invasion and metastasis $(29,30)$. Based on the data from our immunohistochemical staining, the positive rate of HMGB1 expression was $~ 87 \%$ (67 of 77 cases) in ESCC tissue, and esophageal carcinoma patients with positive expression of HMGB1 had poorer overall survival ( $\mathrm{P}=0.007)$ and progression-free survival $(\mathrm{P}=0.008)$ than patients with negative expression of HMGB1. The statistical analysis of clinical characteristics indicated that the expression levels of
HMGB1 were related to clinical cancer stage, distant metastasis and relapse, which indicated that irradiation combined with a new drug targeting HMGB1 may produce better results. Therefore, the effect of downregulating HMGB1 expression on the radiosensitivity of esophageal cancer cells was first explored; subsequently, the effect of overexpressing the HMGB1 gene will be determined in future investigations rendering the present study more convincing.

Previous studies have suggested that HMGB1 participates in DNA damage repair $(6,7,31)$. Its direct binding sites in DNA lesions allow it to play a role in double strand break (DSB) repair (7). The realization of the complete DNA damage response requires the accumulation of $\gamma \mathrm{H} 2 \mathrm{AX}$ (32), and $\mathrm{H} 2 \mathrm{AX}$ phosphorylation has been found to be stimulated by HMGB1 release (33). To determine whether HMGB1 specifically regulated the DNA damage repair induced by irradiation and the radiosensitivity of ESCC cells, the protein levels of $\gamma \mathrm{H} 2 \mathrm{AX}$ were assessed and a colony formation assay was performed with cells deficient in HMGB1 before and after irradiation. As the radiation dose increased and time progressed, the $\gamma \mathrm{H} 2 \mathrm{AX}$ and HMGB1 protein expression levels gradually changed in parallel. Furthermore, the loss of HMGB1 inhibited the synthesis of $\gamma \mathrm{H} 2 \mathrm{AX}$ induced by irradiation, as there was no significant change in the HMGB1-deficient group without irradiation. This phenomenon demonstrated that the existence of HMGB1 is necessary for the generation of phosphorylated $\mathrm{H} 2 \mathrm{AX}$ that promotes DNA damage repair. Similar results were obtained in the colony formation assay; HMGB1-deficient cells revealed a narrow shoulder in the survival curves, indicating that the knockdown of HMGB1 enhanced the radiosensitivity of ESCC cells.

Recent studies have revealed that HMGB1 has the ability to promote tumor growth by different signaling pathways, and the activation of the HMGB1/RAGE interaction was revealed to be correlated with matrix metalloproteinase (MMPs) expression, tumor proliferation, and migration (29). In the present study, it was revealed that a deficiency in HMGB1 suppressed the proliferation of ESCC cells both before and after irradiation in vitro and in vivo, indicating the significant role that HMGB1 played in the growth of esophageal cancer. In clinical studies of HMGB1 detection in nasopharyngeal carcinoma (13), rectal cancer (11), and our own present study of esophageal cancer, comparative studies on metastasis in cancer biopsies revealed that overexpression of HMGB1 may contribute to metastasis. Then, a wound healing and Transwell assays were carried out using 2 esophageal cancer cell lines to confirm the clinical findings aforementioned in vitro. The results demonstrated that silencing of HMGB1 expression with shRNA decreased both the migration and invasion abilities of esophageal tumor cells before and after irradiation, which coincided with the clinical statistical analysis. Subsequently, in seeking the underlying molecular mechanisms, the expression of MMPs, that help tumor cells invade and metastasize by degrading extracellular matrix proteins, were detected (34). The results revealed decreased MMP-2 and MMP-9 expression levels after suppression of HMGB1 expression, corresponding with the reduced migration and invasion abilities. The aforementioned phenomena indicated that HMGB1 facilitated the migration and invasion of esophageal tumor cells by interacting with MMPs. The present results were similar to previous research 
in which it was discovered that HMGB1 increased cell migration through activation of MMP-9 (35).

It has been reported that the downregulation of cyclin D1 is a major factor during the initiation phase of G1 arrest induced by irradiation, and D cyclins primarily activate CDK4 and CDK6, resulting in complex formation that promotes the cells from the $\mathrm{G} 1$ phase into the $\mathrm{S}$ phase by sequestering $\mathrm{p} 21^{\text {cipl }}$ and $\mathrm{p} 27^{\mathrm{kip} 1}$ away from cyclin E-CDK2 (36). In the present study, the effects of HMGB1 expression and irradiation on the transition process of the cell cycle were ascertained as well. Based on data analysis, the suppression of HMGB1 induced G0/G1 arrest before irradiation with a decrease in cyclin D1 and CDK4 levels. Moreover, the irradiation-induced G0/G1 arrest and decrease in cyclin D1 and CDK4 were more notable in HMGB1-deficient cells. The cell cycle analysis and associated-protein evaluation revealed that the suppression of HMGB1 promoted cell cycle arrest at the G0/G1 phase by decreasing cyclin D1 and CDK4 expression.

The present study also analyzed the effect of HMGB1 downregulation on cell apoptosis in vitro. In addition, apoptotic cell percentages in the HMGB1-shRNA groups were significantly greater than those in corresponding negative control groups with irradiation, indicating that the deficiency in HMGB1 induced by shRNA was able to promote apoptosis after irradiation. For the molecular mechanism, we explored the expression of Bcl-2, Bax and caspase-9, all proteins related to the cell apoptosis process. As described in a previous study, the protein Bax increased the formation of oligomers that participate in apoptogenic molecule releases and initiate intrinsic apoptosis; conversely, Bcl-2 decreased apoptosis by controlling the generation of cytochrome $c$ and blocking the oligomerization. Moreover, the expression of caspase- 9 was associated with downstream cytochrome $c$-related apoptosis $(37,38)$. The present study demonstrated that the expression of Bcl-2 decreased and the expression of caspase- 9 and Bax increased after HMGB1-shRNA transfection before and after irradiation. Accordingly, HMGB1 inhibited the apoptosis of esophageal tumor cells after irradiation by regulating pro-apoptotic Bcl-2 family members.

In conclusion, it was revealed the HMGB1 expression, which was higher in ESCC tissue, was negatively related to survival rates and positively associated with malignancy. Suppression of HMGB1 significantly increased the radiosensitivity of ESCC cells by arresting them in the G0/G1 phase and enhancing apoptosis. Irradiation combined with treatments targeting HMGB1 may achieve satisfactory therapeutic effects for esophageal cancer patients.

\section{Acknowledgements}

Not applicable.

\section{Funding}

The present study was supported by the National Natural Science Foundation of China (no. 81872456), the Natural Science Foundation of China of Hebei Province (no. H2017206170), the Medical Research Institute of Hebei Province (no. 20170154) and a grant from the Education Department of Hebei Province (no. CXZZBS2018071).

\section{Availability of data and materials}

All data generated or analyzed during the present study are available from the corresponding author upon reasonable request.

\section{Authors' contributions}

SZ and XY conceived and designed the study. XZ and QL performed the experiments in vitro. $\mathrm{XZ}$ and $\mathrm{NZ}$ constructed the knock down stable cell lines. XZ, XY and NZ performed the experiments in vivo. $\mathrm{XZ}$ and $\mathrm{QL}$ analyzed and interpreted the data. SZ, XY and XZ drafted the manuscript. All authors read and approved the manuscript and agree to be accountable for all aspects of the research in ensuring that the accuracy or integrity of any part of the work are appropriately investigated and resolved.

\section{Ethics approval and consent to participate}

The approval from patients and the Ethics Committee of the Fourth Hospital of Hebei Medical University was obtained for the usage of the specimens for research. All experiments with animals were carried out with the approval of the Animal Care and Use Committee of the Fourth Hospital of Hebei Medical University.

\section{Patient consent for publication}

Not applicable.

\section{Competing interests}

The authors declare that they have no competing interests.

\section{References}

1. Torre LA, Bray F, Siegel RL, Ferlay J, Lortet-Tieulent J and Jemal A: Global cancer statistics, 2012. CA Cancer J Clin 65: 87-108, 2015.

2. Pennathur A, Gibson MK, Jobe BA and Luketich JD: Oesophageal carcinoma. Lancet 381: 400-412, 2013.

3. Ishihara R, Yamamoto S, Iishi H, Takeuchi Y, Sugimoto N, Higashino K, Uedo N, Tatsuta M, Yano M, Imai A, et al: Factors predictive of tumor recurrence and survival after initial complete response of esophageal squamous cell carcinoma to definitive chemoradiotherapy. Int J Radiat Oncol Biol Phys 76: 123-129, 2010.

4. Tang D, Kang R, Zeh HJ III and Lotze MT: High-mobility group box 1 and cancer. Biochim Biophys Acta 1799: 131-140, 2010.

5. Kang R, Zhang Q, Zeh HJ III, Lotze MT and Tang D: HMGB1 in cancer: Good, bad, or both? Clin Cancer Res 19: 4046-4057, 2013.

6. Yuan F, Gu L, Guo S, Wang C and Li GM: Evidence for involvement of HMGB1 protein in human DNA mismatch repair. J Biol Chem 279: 20935-20940, 2004.

7. Lange SS, Mitchell DL and Vasquez KM: High mobility group protein B1 enhances DNA repair and chromatin modification after DNA damage. Proc Natl Acad Sci USA 105: 10320-10325, 2008.

8. Shrivastava S, Mansure JJ, Almajed W, Cury F, Ferbeyre G, Popovic M, Seuntjens J and Kassouf W: The role of HMGB1 in radioresistance of bladder cancer. Mol Cancer Ther 15: 471-479, 2016.

9. Lin HJ, Liu HH, Lin CD, Kao MC, Chen YA, Chiang-Ni C, Jiang ZP, Huang MZ, Lin CJ, Lo UG, et al: Cytolethal distending toxin enhances radiosensitivity in prostate cancer cells by regulating autophagy. Front Cell Infect Microbiol 7: 223, 2017. 
10. Ke S, Zhou F, Yang H, Wei Y, Gong J, Mei Z, Wu L, Yu H and Zhou Y: Downregulation of high mobility group box 1 modulates telomere homeostasis and increases the radiosensitivity of human breast cancer cells. Int J Oncol 46: 1051-1058, 2015.

11. Hongo K, Kazama S, Tsuno NH, Ishihara S, Sunami E, Kitayama $\mathbf{J}$ and Watanabe T: Immunohistochemical detection of high-mobility group box 1 correlates with resistance of preoperative chemoradiotherapy for lower rectal cancer: A retrospective study. World J Surg Oncol 13: 7, 2015.

12. Soumaoro LT, Uetake H, Higuchi T, Takagi Y, Enomoto M and Sugihara K: Cyclooxygenase-2 expression: A significant prognostic indicator for patients with colorectal cancer. Clin Cancer Res 10: 8465-8471, 2004

13. Wu D, Ding Y, Wang S, Zhang Q and Liu L: Increased expression of high mobility group box 1 (HMGB1) is associated with progression and poor prognosis in human nasopharyngeal carcinoma. J Pathol 216: 167-175, 2008.

14. Boonstra JJ, van der Velden AW, Beerens EC, van Marion R, Morita-Fujimura Y, Matsui Y, Nishihira T, Tselepis C, Hainaut P, Lowe AW, et al: Mistaken identity of widely used esophageal adenocarcinoma cell line TE-7. Cancer Res 67: 7996-8001, 2007.

15. Livak KJ and Schmittgen TD: Analysis of relative gene expression data using real-time quantitative PCR and the $2^{-\Delta \Delta C_{\mathrm{T}}}$ method. Methods 25: 402-408, 2001.

16. Yang XX, Ma M, Sang MX, Wang XX, Song H, Liu ZK and Zhu SC: Radiosensitization of esophageal carcinoma cells by knockdown of RNF2 expression. Int J Oncol 48: 1985-1996, 2016.

17. Zhang Y: Epidemiology of esophageal cancer. World J Gastroenterol 19: 5598-5606, 2013.

18. Sohun M and Shen H: The implication and potential applications of high-mobility group box 1 protein in breast cancer. Ann Transl Med 4: 217, 2016.

19. Jiang H, Hu X, Zhang $\mathrm{H}$ and Li W: Down-regulation of LncRNA TUG1 enhances radiosensitivity in bladder cancer via suppressing HMGB1 expression. Radiat Oncol 12: 65, 2017.

20. Shi Z, Huang Q, Chen J, Yu P, Wang X, Qiu H, Chen Y and Dong Y: Correlation of HMGB1 expression to progression and poor prognosis of adenocarcinoma and squamous cell/adenosquamous carcinoma of gallbladder. Am J Transl Res 7: 2015-2025, 2015.

21. Tabata C, Shibata E, Tabata R, Kanemura S, Mikami K, Nogi Y, Masachika E, Nishizaki T and Nakano T: Serum HMGB1 as a prognostic marker for malignant pleural mesothelioma. BMC Cancer 13: 205, 2013.

22. Peng T, Hu M, Wu T, Chen Z, Zhang C, Huang S and Zhou X: Effects of high-mobility group box 1 knockdown on proliferation, migration and invasion of the HONE-1 human nasopharyngeal carcinoma cell line. Mol Med Rep 12: 7531-7537, 2015.

23. Suzuki Y, Mimura K, Yoshimoto Y, Watanabe M, Ohkubo Y, Izawa S, Murata K, Fujii H, Nakano T and Kono K: Immunogenic tumor cell death induced by chemoradiotherapy in patients with esophageal squamous cell carcinoma. Cancer Res 72: 3967-3976, 2012.

24. Gebhardt C, Riehl A, Durchdewald M,Németh J,Fürstenberger G, Müller-Decker K, Enk A, Arnold B, Bierhaus A, Nawroth PP, et al: RAGE signaling sustains inflammation and promotes tumor development. J Exp Med 205: 275-285, 2008.
25. Liu Z, Falo LD Jr and You Z: Knockdown of HMGB1 in tumor cells attenuates their ability to induce regulatory $T$ cells and uncovers naturally acquired CD8 T cell-dependent antitumor immunity. J Immunol 187: 118-125, 2011.

26. van Beijnum JR, Nowak-Sliwinska P, van den Boezem E, Hautvast P, Buurman WA and Griffioen AW: Tumor angiogenesis is enforced by autocrine regulation of high-mobility group box 1 . Oncogene 32: 363-374, 2013

27. Giavara S, Kosmidou E, Hande MP, Bianchi ME, Morgan A, d'Adda di Fagagna F and Jackson SP: Yeast Nhp6A/B and mammalian Hmgbl facilitate the maintenance of genome stability. Curr Biol 15: 68-72, 2005.

28. Tang D, Kang R, Livesey KM, Kroemer G, Billiar TR, Van Houten B, Zeh HJ III and Lotze MT: High-mobility group box 1 is essential for mitochondrial quality control. Cell Metab 13: 701-711, 2011

29. Taguchi A, Blood DC, del Toro G, Canet A, Lee DC, Qu W, Tanji N, Lu Y, Lalla E, Fu C, et al: Blockade of RAGE-amphoterin signalling suppresses tumour growth and metastases. Nature 405: $354-360,2000$

30. Livesey KM, Kang R, Vernon P, Buchser W, Loughran P, Watkins SC, Zhang L, Manfredi JJ, Zeh HJ III, Li L, et al: p53/HMGB1 complexes regulate autophagy and apoptosis. Cancer Res 72: 1996-2005, 2012.

31. Krynetskaia NF, Phadke MS, Jadhav SH and Krynetskiy EY: Chromatin-associated proteins HMGB1/2 and PDIA3 trigger cellular response to chemotherapy-induced DNA damage. Mol Cancer Ther 8: 864-872, 2009

32. Soutoglou E and Misteli T: Activation of the cellular DNA damage response in the absence of DNA lesions. Science 320 1507-1510, 2008.

33. Krynetskaia N, Xie H, Vucetic S, Obradovic Z and Krynetskiy E: High mobility group protein B1 is an activator of apoptotic response to antimetabolite drugs. Mol Pharmacol 73: 260-269, 2008.

34. Kessenbrock K, Wang CY and Werb Z: Matrix metalloproteinases in stem cell regulation and cancer. Matrix Biol 44-46: 184-190, 2015.

35. Lee CC, Wang CN, Lee YL, Tsai YR and Liu JJ: High mobility group box 1 induced human lung myofibroblasts differentiation and enhanced migration by activation of MMP-9. PLoS One 10: $\mathrm{e} 0116393,2015$.

36. Agami R and Bernards R: Distinct initiation and maintenance mechanisms cooperate to induce $\mathrm{G} 1$ cell cycle arrest in response to DNA damage. Cell 102: 55-66, 2000

37. Cheng P, Dai W, Wang F, Lu J, Shen M, Chen K, Li J, Zhang Y, Wang C, Yang J, et al: Ethyl pyruvate inhibits proliferation and induces apoptosis of hepatocellular carcinoma via regulation of the HMGB1-RAGE and AKT pathways. Biochem Biophys Res Commun 443: 1162-1168, 2014.

38. Allan LA and Clarke PR: Apoptosis and autophagy: Regulation of caspase-9 by phosphorylation. FEBS J 276: 6063-6073, 2009. 